\title{
Annals of Microbiology and Research
}

ISSN: $2642-4533$

Commentary

DOI: $10.36959 / 958 / 575$

\section{COVID-19: Where we Started and Where we Stand}

\author{
Mohammad Ammad Ud Din ${ }^{1 *}$, Hemanth Boppana ${ }^{2}$ and Hassan Liaqat ${ }^{3}$ \\ ${ }^{1}$ Department of Internal Medicine, Rochester General Hospital, USA \\ ${ }^{2}$ Port of Spain General Hospital, West Indies \\ ${ }^{3}$ Henry Ford Allegiance Health, USA
}

\begin{abstract}
Coronavirus disease 2019 (COVID-19) is a new infectious disease classified as a pandemic by the World Health Organization on March $11^{\text {th }}, 2020$. It is caused by the SARS-CoV 2 betacoronavirus and emerged in Wuhan Province, China in late December 2019. Since then, it has spread to 179 countries with over 800,000 confirmed cases. We briefly review the epidemiology and measures to reduce exposure for healthcare workers and the general public as well as some data from early clinical trials in search of targeted therapy.
\end{abstract}

Keywords

nCov2019, Coronavirus, Viral pneumonia, Covid-19, Pandemic

\section{Introduction}

As of mid-March 2020, the novel Coronavirus disease now being termed COVID-19 has brought everyday life in major cities around the world to a halt. The outbreak which was first reported in late December 2019 when several local health care facilities in Wuhan, China identified clusters of patients with atypical viral pneumonia and linked these cases to the Huanan Seafood market [1]. Within less than a month, the virus traveled across the world, infecting people throughout Asia, the Middle East, Europe, and the Americas, where the first case was confirmed in Washington in late January 2020 [2]. The virus responsible for causing COVID-19 was isolated as genus betacoronavirus and named Severe Acute Respiratory Syndrome Coronavirus 2 (SARS-CoV2). It is zoonotic in origin and linked to a fatal illness with another betacoronavirus causing the Severe Acute Respiratory Syndrome (SARS) outbreak in Guangdong province, China in 2002-03. The SARS-CoV2 is nearly $96 \%$ identical at the whole genome level to a bat Coronavirus, suggesting bats are likely the host [3], but whether the microbe is transmitted directly from bats or through an intermediate host is not confirmed.

In the early stages, it was presumed that the virus was spread through direct contact with animals, but person-to-person transmission is now well established. The main route of transmission is via respiratory droplets, but direct inoculation from contact with infected surfaces and aerosol are also implicated. The virus was isolated in the feces of confirmed patients in Wuhan and the United States, suggesting the possibility of fecal-oral transmission but this is yet to be confirmed [2].
The incubation period is between 2 and 14 days after exposure with the median incubation period being 4 days with fever $(87.9 \%)$ and cough $(67.7 \%)$ being the most common symptoms [2]. Cases of asymptomatic carriers have been reported but the extent of is unknown given the lack of largescale serological screening. At the time of writing this article, there are 823,479 confirmed cases in 179 countries with 39,545 deaths [4]. A summary of 72,314 cases from the Chinese Centers for Disease Control and Prevention (CDC) stated that the spectrum of disease varied from mild to critical, with mild disease (no symptoms to mild pneumonia) reported in $81 \%$, severe disease (dyspnea, hypoxia, > 50\% lung involvement on imaging within $24-48$ hours) in $14 \%$ and critical disease (respiratory failure, shock, multi-organ dysfunction) reported in $5 \%$. The overall case-fatality rate was $2.3 \%$. Most fatal cases occurred in those with advanced age or underlying medical co-morbidities [5].

There is currently no vaccine to prevent COVID-19 although a clinical trial is underway in the US. Public preventive health measures outlined by CDC to reduce transmission of infection include diligent hand washing, social distancing with

*Corresponding author: Mohammad Ammad Ud Din, Department of Internal Medicine, Rochester General Hospital, 1425 Portland Avenue, Rochester, New York, USA

Received: March 31, 2020

Accepted: April 24, 2020

Published online: April 26, 2020

Citation: Din MA, Boppana H, Liaqat H (2020) COVID-19: Where we Started and Where we Stand. Ann Microbiol Res $4(1): 100-101$ 
sick persons and other persons if COVID-19 in the community, respiratory hygiene (covering when coughing or sneezing) and quarantining based on symptoms and level of risk $[6,7]$. In the health care setting, there are guidelines [8] on assessing and triaging patients with respiratory symptoms to minimize exposure including placing a facemask on the patient and placing them in an examination room with the door closed, using appropriate personal protective equipment (PPE) for a person under investigation and confirmed cases as well as hand hygiene with an alcohol-based rub before and after all patient contact. For patients requiring admission into the intensive care unit (ICU), multiple trials being conducted in search of targeted therapy, few of which have been published. The addition of lopinavir-ritonavir to standard therapy did not show any benefit in patients with severe Covid-19 while a small trial supported the use of azithromycin with hydroxychloroquine in hospitalized patients $[9,10]$. A case series of five critically ill patients with respiratory failure demonstrated benefit of the use of convalescent plasma containing neutralizing antibody [11].

With the number of cases rising exponentially, preventive health measures remain the cornerstone to slow the spread of the virus until a targeted therapy is developed.

\section{Declaration of Interest Statement}

The authors declared no potential conflicts of interest with respect to the research, authorship, and/or publication of this article.

\section{References}

1. Zhu N, Zhang D, Wang W, et al. (2020) A novel coronavirus from patients with pneumonia in China, 2019. N Engl J Med 382: 727733.

2. Holshue ML, DeBolt C, Lindquist S, et al. (2020) First Case of 2019 Novel coronavirus in the United States. N Engl J Med 382: 929936.

3. Zhou P, Yang $X$, Wang $X$, et al. (2020) A pneumonia outbreak associated with a new coronavirus of probable bat origin. Nature 579: 270-273.

4. https://coronavirus.jhu.edu/map.html

5. Wu Z, McGoogan JM (2020) Characteristics of and important lessons from the coronavirus disease 2019 (COVID-19) Outbreak in China: Summary of a report of 72314 cases from the Chinese center for disease control and prevention. JAMA.

6. https://www.cdc.gov/coronavirus/2019-ncov/prepare/index. html

7. https://www.cdc.gov/coronavirus/2019-ncov/php/risk-assessment.html

8. https://www.cdc.gov/coronavirus/2019-ncov/hcp/caring-for-patients.html

9. Cao B, Wang Y, Wen D, et al. (2020)bA trial of Lopinavir-Ritonavir in adults hospitalized with severe covid-19. N Engl J Med.

10. https://doi.org/10.1016/j.ijantimicag.2020.105949

11. Shen C, Wang Z, Zhao F, et al. (2020) Treatment of 5 critically III patients with COVID-19 with convalescent plasma. JAMA.

DOI: $10.36959 / 958 / 575$

Copyright: (c) 2020 Din MA, et al. This is an open-access article distributed under the terms of the Creative Commons Attribution License, which permits unrestricted use, distribution, and reproduction in any medium, provided the original author and source are credited. 